Article

\title{
Screening Mechanism and Properties of a Cantilevered Vibrating Sieve for Particles Processing
}

\author{
Liping Peng ${ }^{1,2}{ }^{\mathbb{C}}$, Huihui Feng ${ }^{1, *}$, Zhenqian Wang ${ }^{3, *} \mathbb{C}$, Haoyu Wang ${ }^{1}$, Huan Yang ${ }^{2}$ and \\ Huan Huang 1 \\ 1 College of Mechanical and Electrical Engineering, Hohai University, Changzhou 213001, China; \\ plp_hhu@163.com (L.P.); 181319010025@hhu.edu.cn (H.W.); Hhuan1997@163.com (H.H.) \\ 2 Department of Mechanical and Electrical Engineering, Changzhou Liu Guojun Vocational Technology \\ College, Changzhou 213001, China; yanghuan10029@163.com \\ 3 School of Mechanical and Vehicle Engineering, Linyi University, Linyi 276000, China \\ * Correspondence: fenghh@hhu.edu.cn (H.F.); wangzhenqian@lyu.edu.cn (Z.W.)
}

Received: 16 October 2019; Accepted: 12 November 2019; Published: 15 November 2019

\begin{abstract}
Screening of fine wet particles or near-aperture particles by traditional screen devices is often not quite effective for sieve plugging. Different from traditional rigid regular mesh sieves, a cantilevered vibrating sieve (CVS) with open screen holes, composed of cantilevered sieve rods, was proposed in this paper. The CVS proved to have a higher screen-penetrating probability relative to traditional sieves. By establishing a bending vibration model for the CVS, it can be found that additional vibrations may emerge during the screen body motion, and a smaller difference between the natural circular frequency and the vibration frequency will achieve a larger vibration of cantilevered sieve rod. On this basis, this investigation also analyzed anti-plugging mechanism of the CVS and systematically discussed the influence laws of the geometric parameters and vibration parameters of the sieve on screening efficiency by the discrete element method.
\end{abstract}

Keywords: cantilevered vibrating sieve; sieve plugging; bending vibration; screening efficiency; simulation; discrete element method

\section{Introduction}

Screening is the most fundamental technological process in coal preparation and metallurgy. In industrial practice, vibration screens are used for particle classification, dehydration, medium draining, and other operations [1]. Screening of fine wet particles by traditional screen devices is often not quite effective because of the existence of thin water film on the surface of fine wet particles. Under the combined action of the liquid bridge force and water film surface tension, adjacent particles cluster together and adhere to the sieve. With the extension of screening time, more and more particles adhere to the sieve, thus eventually forming a cover film that plugs the screen sieve [2,3]. Moreover, near-aperture particles are close to screen holes in size, so they can very quickly get stuck in screen holes, resulting in sieve plugging [4]. One way of solving this problem is to increase sieve acceleration; however, due to the direct rigid coupling between sieve and screen body, an excessive sieve acceleration inevitably increases the acceleration of screen body, influences its structural strength and fatigue life, and even causes structural damage [5].

At present, elastic sieves [6] and flip-flow sieves [7] can solve the problem of plugging encountered in the screening of fine wet particles to some extent. Relying on their elastic vibration, elastic sieves may experience a geometric deformation, thus further loosening fine wet particles and cracking the cover film $[8,9]$. By contrast, the flip-flow sieve made of elastic polyurethane would engage in reciprocating bending-tensioning motion and has a higher amplitude and acceleration relative to traditional rigid 
sieves. These two kinds of screen sieves help to overcome the adhesive force of the cover film, and promote the dispersion of adhered clustered particles [10-12].

According to the studies on the screening property of vibrating screens, discrete element method (DEM)-based numerical simulation can effectively save physical experiment time and increase analysis efficiency. So far, DEM has been extensively applied on vibrating screens, such as the circular vibrating screen $[13,14]$, the linear vibrating screen [15-17], the elliptical vibrating screen [18], and the banana screen $[19,20]$. Studies in this field mainly focus on rigid rectangular or circular mesh sieves, which do not deform during screening. When they are utilized to process near-aperture particles or fine wet particles, the plugging may reduce the screening efficiency of vibrating screens [21].

Based on studies about elastic sieves, and as the cantilevered vibration under foundation displacement excitation is more significant than fixed end vibration, this paper will propose a cantilevered vibrating sieve (CVS), analyze its anti-plugging mechanism and screen-penetrating probability, establish a vibration characteristic calculation model for the anti-plugging mechanism, and investigate its screening performances through the discrete element method.

\section{Construction of a CVS}

Traditional vibrating screens mostly contain an enclosed screening hole structure, such as the rectangular screen hole and circular screen hole $[2,18]$. In contrast, the proposed CVS is composed of multiple cantilevered sieve rods, which are inserted into the mounting base in parallel to achieve open screen holes, as shown in Figure 1. The length and diameter of the cantilevered sieve rod are $\mathrm{L}$ and $\mathrm{q}$, respectively. The spacing between two adjacent rods is s.

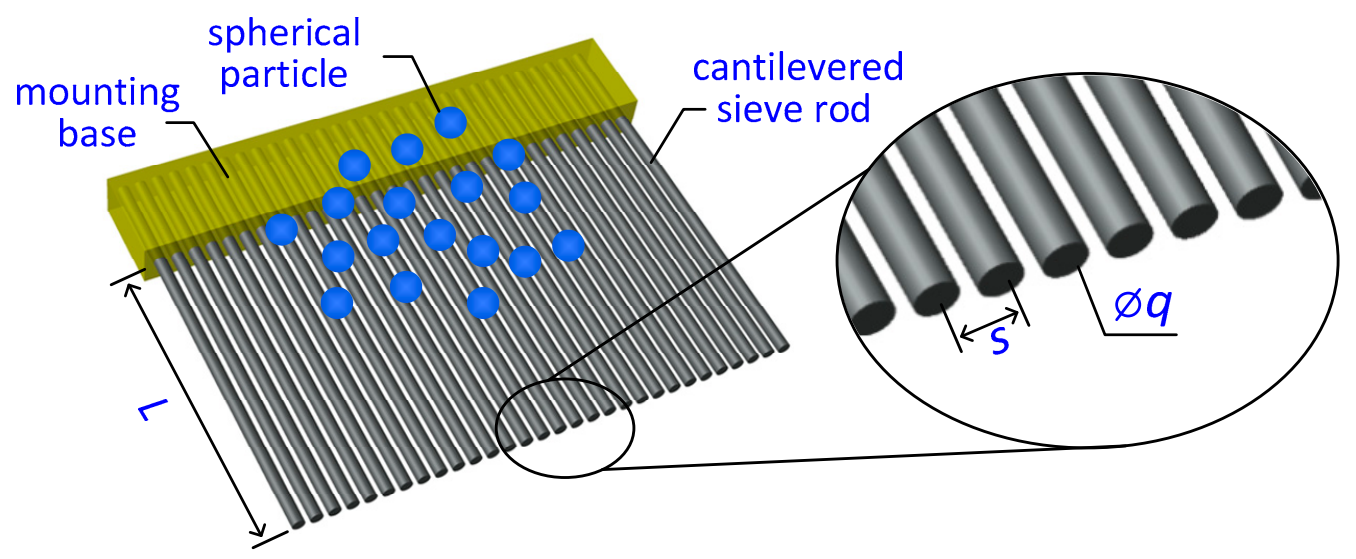

Figure 1. Mechanical structure of a cantilevered vibrating sieve (CVS).

Here we consider the property of particles going through the two kinds of screen holes. As illustrated in Figure 2, for a traditional rectangular screen hole with size of $\mathrm{L} \times \mathrm{H}$, if a spherical particle with $\mathrm{d}(\mathrm{d}<\mathrm{H}<\mathrm{L})$ in diameter falls into it, it freely passes through the screen hole to be an undersized product. On the other hand, a spherical particle that fails to pass through this screen hole may successfully pass through the next one, or eventually become an oversized product. Thus, for a spherical particle to successfully pass through the screen hole, the center of the falling particle must be within the dashed box in the middle, in which case the area of the dashed box is $(\mathrm{L}-\mathrm{d}) \times(\mathrm{H}-\mathrm{d})$. For the CVS, screen holes are similar to open rectangular holes, which are not subject to the boundary constraint on the right. Thus, the particle falling area that allows smooth screening is also the dashed box in the middle, with an area of $(\mathrm{L}-0.5 \mathrm{~d}) \times(\mathrm{H}-\mathrm{d})$. 
(a)

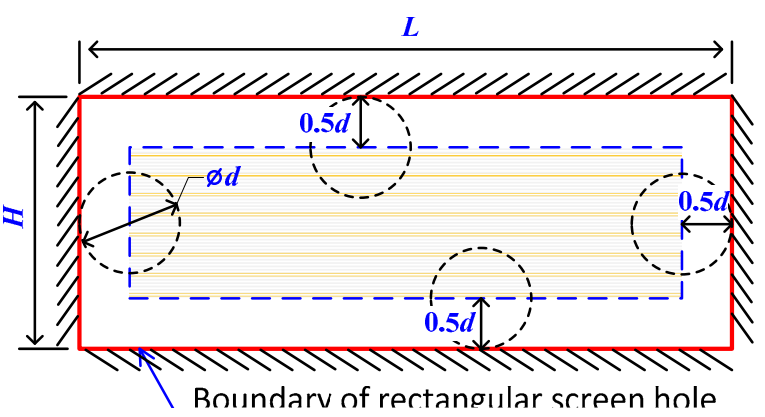

(b)

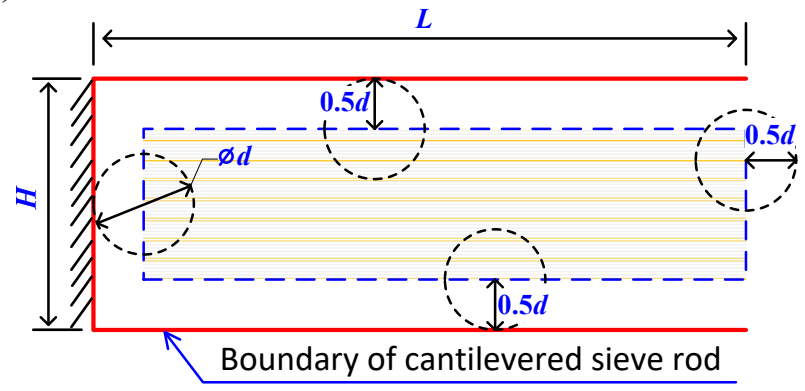

Figure 2. Schematic diagram of particles passing through screen holes of (a) a traditional rectangular screen and (b) a CVS.

It can be conceived that the number of times of particles penetrating through screen holes is directly proportional to the area. Also, the number of times of particles being fed to screen holes is directly proportional to screen hole area $\mathrm{L} \times \mathrm{H}$. For this reason, the probability of particles penetrating through screen holes can be determined by the ratio of the two areas:

For traditional rectangular screen holes, the screen-penetrating probability is:

$$
p_{1}=\frac{(L-d)(H-d)}{L H},
$$

while for the CVS, the screen-penetrating probability is:

$$
p_{2}=\frac{(L-0.5 d)(H-d)}{L H},
$$

In view of the following relationship:

$$
\frac{p_{2}}{p_{1}}=\frac{L-0.5 d}{L-d}>1
$$

thus, the CVS has a higher screen-penetrating probability relative to traditional sieves, and this fundamentally determines that the CVS can also achieve a high screening efficiency.

\section{Screening Mechanism of Cantilevered Vibrating Sieve (CVS) Based on Motion Characteristics}

\subsection{Motion Characteristics of Cantilevered Vibrating Sieve (CVS)}

Any cantilevered sieve rod of the CVS is a thin and long rod with a certain degree of elasticity. Given that the vibration direction of the screen body is not vertical to sieve rods, a tangential additional bending vibration relative to sieve rod section may be very easily yielded in the vibration process from Position A to Position C, as shown in Figure 3. 


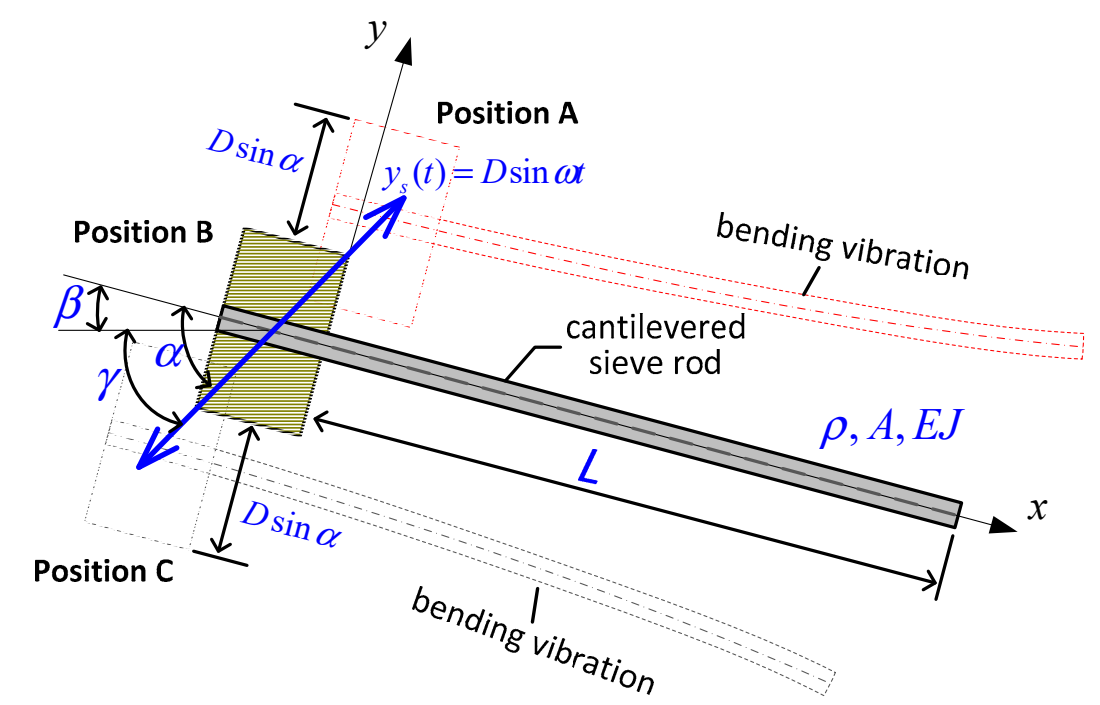

Figure 3. Cantilevered vibrating sieve (CVS) vibration model during screen body motion.

Generally, the screening body of a vibrating screen usually oscillates in a simple harmonic motion. Assuming the vibration equation of screen body with respect to time $t$ is $y_{s}(t)=D \sin \omega t$, where $D$ is the vibration amplitude and $\omega$ is the vibration circular frequency. The included angle between the vibration direction of screen body and sieve rods is $\alpha$, the sieve inclination angle is $\beta$, and thus the vibration direction angle is $\gamma=\alpha-\beta$. The length and cross-sectional area of the cantilevered sieve rod are $\mathrm{L}$ and $\mathrm{A}$, respectively. Thus, in the coordinate system xoy of the screen body, the partial differential equation of additional bending vibration $y(x, t)$ is:

$$
E J \frac{\partial^{4} y(x, t)}{\partial x^{4}}+\rho A \frac{\partial^{2} y(x, t)}{\partial t^{2}}=-\rho A \cdot \frac{\mathrm{d}^{2} y_{s}(t)}{\mathrm{d} t^{2}} \cdot \sin \alpha \quad(0 \leq x \leq L),
$$

where $E$ and $\rho$ are the Young's modulus and the density the rod material, respectively, $J$ is the second moment of the cross-sectional area with respect to the neutral axis.

For Equation (4), the additional bending vibration equation of cantilevered sieve rods can be assumed as [22]:

$$
y(x, t)=\sum_{i=1}^{\infty} C_{i} Y_{i}(x) \sin \omega t
$$

where $Y_{\mathrm{i}}(x)$ is the ith-order natural mode of vibration. For constant-section homogeneous rods like the cantilevered sieve rods, the following relationship holds:

$$
Y_{i}(x)=\cosh \beta_{i} x-\cos \beta_{i} x-\frac{\sinh \beta_{i} L-\sin \beta_{i} L}{\cosh \beta_{i} L+\cos \beta_{i} L}\left(\sinh \beta_{i} x-\sin \beta_{i} x\right),
$$

where the value of $\beta_{i}$ is determined by the formula $\cos \beta_{i} L \cdot \cosh \beta_{i} L+1=0$. The solution to this nonlinear equation is shown in Table 1.

Table 1. Parameterized representation of the solution.

\begin{tabular}{ccccc}
\hline $\boldsymbol{i}$ & $\mathbf{1}$ & $\mathbf{2}$ & $\mathbf{3}$ & $\mathbf{> 3}$ \\
\hline$\beta_{i}$ & $1.8751 / L$ & $4.6941 / L$ & $7.8548 / L$ & $(2 i-1) \pi / 2 L$ \\
\hline
\end{tabular}


After substituting Equation (5) into Equation (4) and multiplying both sides of the equation by $Y i(x)$, integration is performed within the range of cantilevered sieve rod length, and the orthogonality of the vibration mode function is used to obtain:

$$
C_{i}=\frac{D \omega^{2} \sin \alpha}{\left|\omega_{i}^{2}-\omega^{2}\right|} \frac{\int_{0}^{L} Y_{i}(x) \mathrm{d} x}{\int_{0}^{L} Y_{i}^{2}(x) \mathrm{d} x}
$$

where $\omega_{i}$ is natural circular frequency and determined by:

$$
\omega_{i}=\beta_{i}^{2} \sqrt{\frac{E J}{\rho A}},
$$

By substituting Equation (7) and the relationship of $\alpha=\gamma+\beta$ into Equation (5), then, during the vibration process of the screen body, the additional bending vibration of a cantilevered sieve rod can be expressed as:

$$
y(x, t)=\left[\sum_{i=1}^{\infty} \frac{D \omega^{2} \sin (\beta+\gamma)}{\left|\omega_{i}^{2}-\omega^{2}\right|} \frac{\int_{0}^{L} Y_{i}(x) \mathrm{d} x}{\int_{0}^{L} Y_{i}^{2}(x) \mathrm{d} x} Y_{i}(x)\right] \sin \omega t,
$$

Apparently, according to the analysis of Equation (9), the additional bending vibration of a cantilevered sieve rod is closely related to the length of cantilevered sieve rod $L$, the sieve inclination angle $\beta$, the vibration direction angle $\gamma$, the vibration amplitude $D$ and the vibration frequency $\omega$. Such additional bending vibrations along the axial direction of sieve rod have different amplitudes. In addition, when the vibration frequency of screen body closely approaches $\omega_{i}$, namely, the $\omega_{i}^{2}-\omega^{2} \rightarrow 0$, the additional bending vibration of cantilevered sieve rod reaches its peak value. Generally, a smaller difference between $\omega_{i}$ and $\omega$ will achieve a larger vibration of the cantilevered sieve rod. It should be noted that the natural circular frequency with a unit of $\mathrm{rad} / \mathrm{s}$ above can be converted to be the natural frequency with unit of $\mathrm{Hz}$ by multiplying $2 \pi$.

\subsection{Anti-Plugging Mechanism of Cantilevered Vibrating System (CVS)}

As analyzed above, the CVS has a higher opening rate and fewer constraints to sieve rods compared to traditional vibration screens. Besides this, if the screen body is manually set to oscillate at a vibration frequency around the natural circular frequency of cantilevered sieve rod, a large additional bending vibration will be produced to eject the plugging material on the sieve. Hence, the anti-plugging mechanism of a CVS can be summarized and is displayed in Figure 4. During a material feeding process, the oversized product hits against the sieve rods when moving along the sieve rods from the feeding end to the discharge end. Such impact induces an external outward pull to crack the clusters of wet-sticky particle swarm. Moreover, the cantilevered sieve rods may also experience a longitudinal shift to yield a larger space for near-aperture particles rubbing motion. This further accelerates the subsidence and lateral motion of particle then reduces the sieve plugging. 


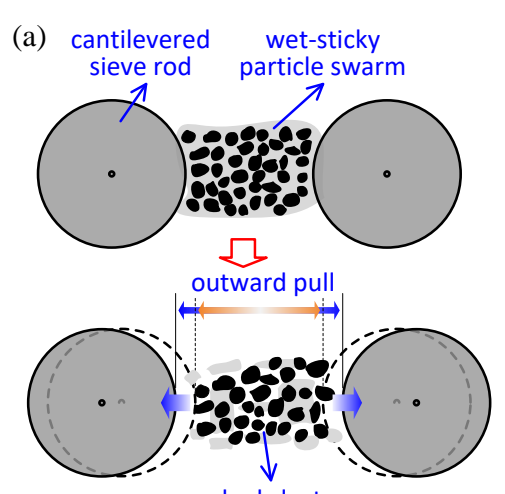

cracked clusters

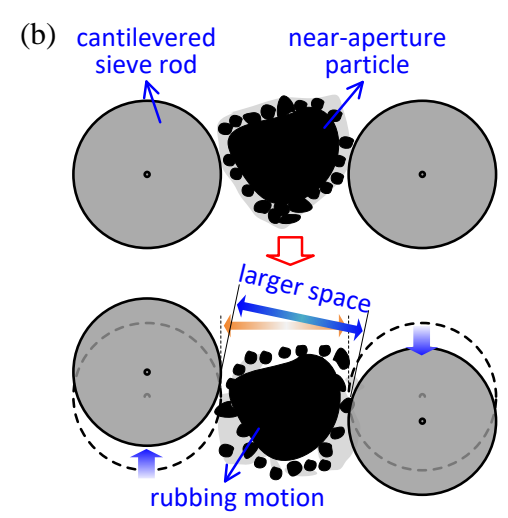

Figure 4. Anti-plugging mechanism of cantilevered vibrating sieve (CVS) induced by (a) transverse shift and (b) longitudinal shift of cantilevered sieve rod.

\section{Establishment of Screening Simulation}

In order to investigate the influence of geometric parameters and vibration parameters on the screening efficiency of the CVS, this investigation performed a numerical simulation of the screening process under various conditions, such as different length of cantilevered sieve rod, sieve inclination angle, vibration direction angle, vibration amplitude, and vibration frequency. These influence factors are common in studying screening properties of other kinds of vibrating screen in [1-3,5,6,13-20].

In this investigation, all the simulations were conducted by the commercial Discrete Element Method (DEM) software named EDEM (Version 2.7). Figure 5 shows the CVS model used in the simulation. The diameter of cantilevered sieve rods (d) is $6 \mathrm{~mm}$, the spacing between two adjacent rods (s) is $16.5 \mathrm{~mm}$, which means the screen hole size is $\mathrm{s}-\mathrm{d}=10.5 \mathrm{~mm}$. Besides this, the density of coal and cantilevered sieve rod, the Poisons ratio, the Young's modulus of coal and cantilevered sieve rod, and the restitution coefficient, sliding friction coefficient, rolling friction coefficient, and the simulation time step are all the same as those in Reference [18].

(a)

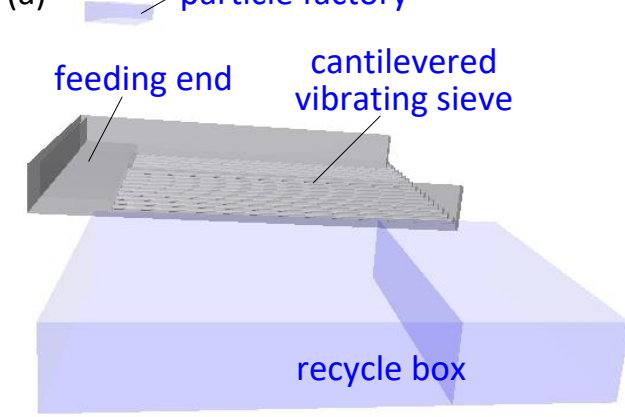

(b)

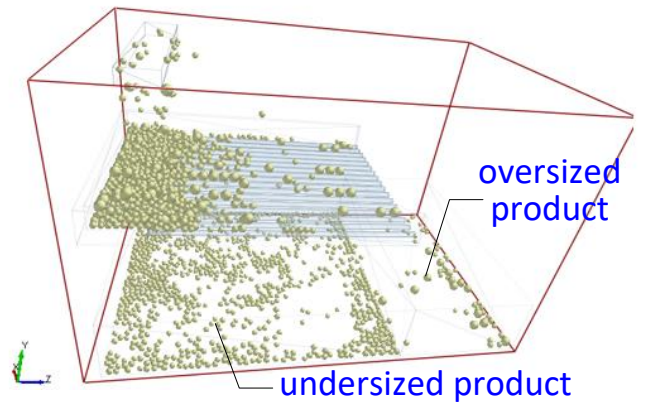

Figure 5. Discrete element method (DEM) model of a cantilevered vibrating sieve (CVS) without particles (a) and with particles (b).

The screening material is coal particle. Based on the screen hole size, this investigation sets six different coal particle sizes, and their corresponding mass ratios are shown in Table 2. The mass of the coal particles whose sizes are smaller than the screen hole size accounts for $81.4 \%$ of the total mass.

Table 2. Sizes and their mass ratios of coal particles.

\begin{tabular}{ccccccc}
\hline Particle Sizes (mm) & 8 & 9 & 10 & 11 & 12 & 16 \\
\hline Number ratio (\%) & 37.7 & 37.7 & 18.9 & 1.9 & 1.9 & 1.9 \\
\hline Mass ratio (\%) & 27.2 & 38.5 & 15.7 & 3.4 & 4.5 & 10.7 \\
\hline
\end{tabular}




\section{Analysis of Simulation Results}

After setting material attributes and motion parameters, this investigation conducted the screening simulation, as shown in Figure 6, and analyzed the numerical data from each group.

To evaluate the screen property, the overall screening efficiency of the CVS from the simulation results was calculated by the following formula [20]:

$$
\eta=\frac{m}{M \cdot \lambda} \times 100 \%,
$$

where $\eta$ is the screening efficiency, $\mathrm{m}$ is the mass of the undersized product, $M$ is the total mass of the raw coal material, and $\lambda$ is content of coal materials whose particle sizes are smaller than screen hole size.

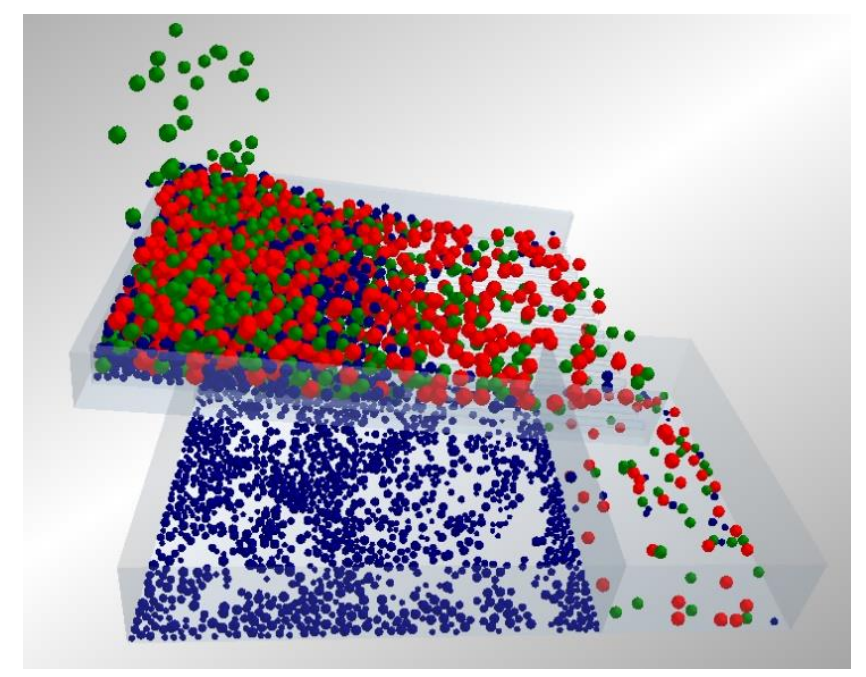

Figure 6. Schematic of the screening experiment process.

\subsection{Influence of Geometric Parameters on Screening Efficiency}

Figure 7 demonstrates the screening efficiency with different length of cantilevered sieve rod. In this case, the sieve inclination angle $\beta$ was set to be $0^{\circ}$, and the simulated vibration parameters are: $\gamma=40^{\circ}, \omega=16 \mathrm{~Hz}, \mathrm{D}=2 \mathrm{~mm}$. Note that the vibration parameters are tentatively determined by the parameters available in Reference [23].With the increase of rod length, screening efficiency has an obvious increasing trend. When rod length is small, many particles are thrown out of the screening area after bouncing on the sieve, which leads to the reduction of undersized product and screening efficiency. With the increase of rod length, the screening time of particles on the sieve becomes longer, leading to a gradually increased screening efficiency. When rod length increases to about $380 \mathrm{~mm}$, screening efficiency reaches its maximum of $68.60 \%$. A further increase of the length causes screening efficiency to decline to some extent while staying high. 


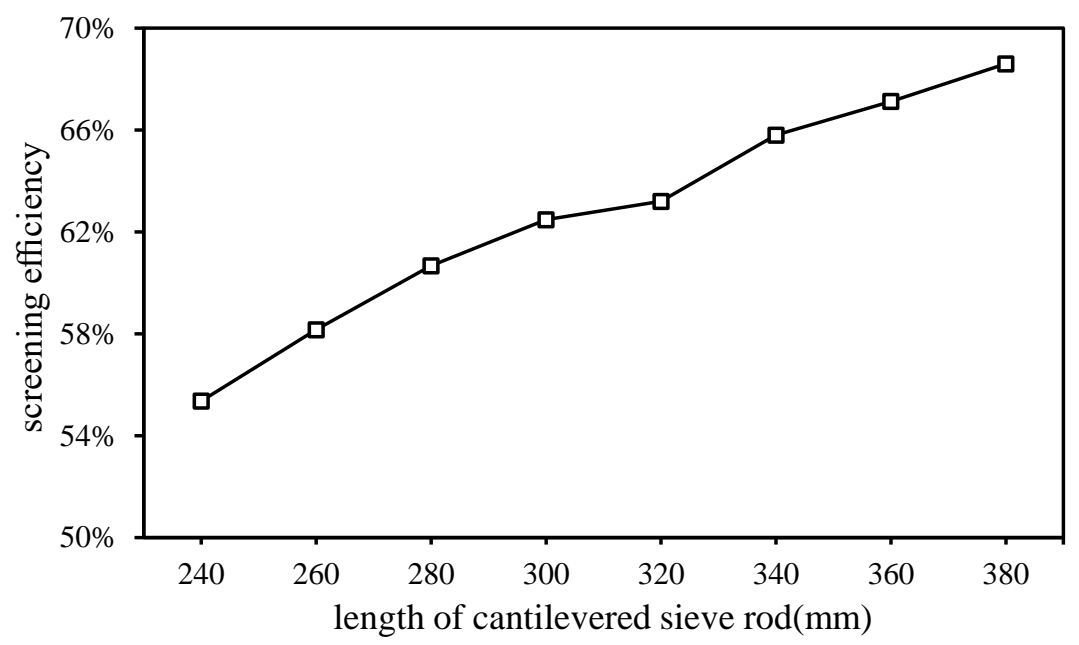

Figure 7. Screening efficiency of a cantilevered vibrating sieve (CVS) for different length of cantilevered sieve rod.

For the case when the length of cantilevered sieve rod was $380 \mathrm{~mm}$, in which case the vibration parameters are: $\gamma=40^{\circ}, \omega=16 \mathrm{~Hz}, \mathrm{D}=2 \mathrm{~mm}$, respectively, the simulation also investigated the screening efficiency under sieve inclination angles of $0^{\circ}-16^{\circ}$, and the results are shown in Figure 8 . Clearly, with the increase of sieve inclination angle, screening efficiency has a declining trend. The reason is perhaps that the increase of sieve inclination angle increases the motion velocity of materials on the sieve. As a result, some particles at the top of the material layer leave the working area before screening. According to Figure 8, when the sieve inclination angle is $14^{\circ}$, screening efficiency drops below $50 \%$. On the other hand, when the angle is small, the material moves slowly and receives adequate screening, and thus high screening efficiency can be maintained.

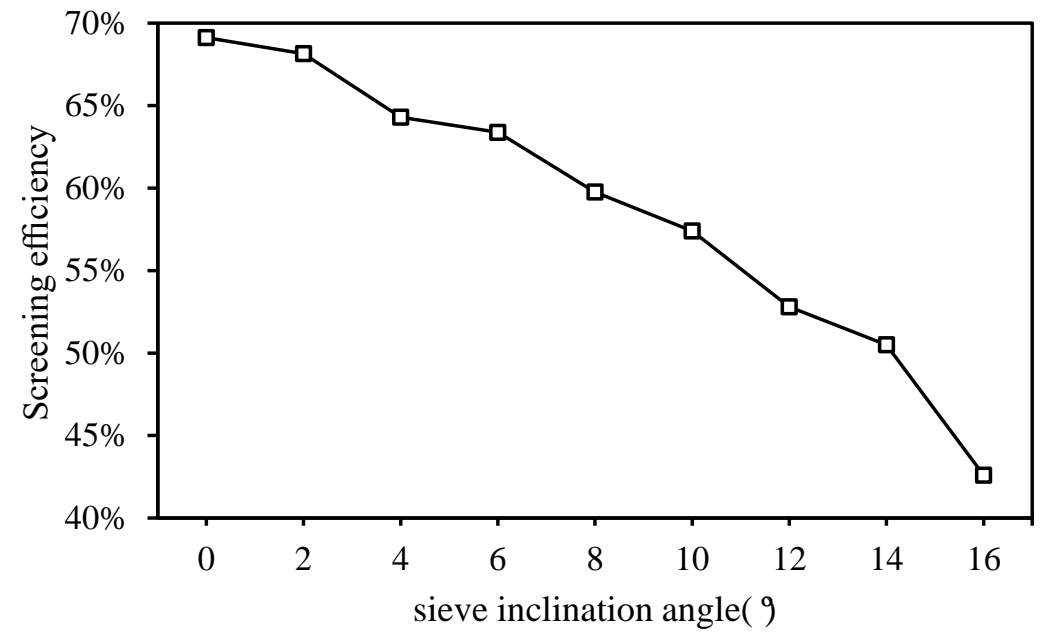

Figure 8. Screening efficiencies of a cantilevered vibrating sieve (CVS) for different sieve inclination angle.

\subsection{Influence of Vibration Parameters on Screening Efficiency}

In studying the influence of vibration parameters on screening efficiency, the geometric parameters were fixed to be: The sieve inclination angle $\beta=0^{\circ}$ and the length of cantilevered sieve $\operatorname{rod} \mathrm{L}=380 \mathrm{~mm}$. On the condition that the vibration amplitude $\mathrm{D}=2 \mathrm{~mm}$ and the vibration circular frequency $\omega=16 \mathrm{~Hz}$, this investigation also analyzed the screening efficiency when the vibration direction angle was in the range of $30^{\circ}-65^{\circ}$ (Figure 9). Obviously, when the vibration direction angle is within this range, the screening efficiency has no significant differences and lies between $56 \%$ and $68 \%$. 
The screening efficiency reaches its maximum of $68.02 \%$ at $45^{\circ}$, and then begins to drop abruptly when the angle increases.

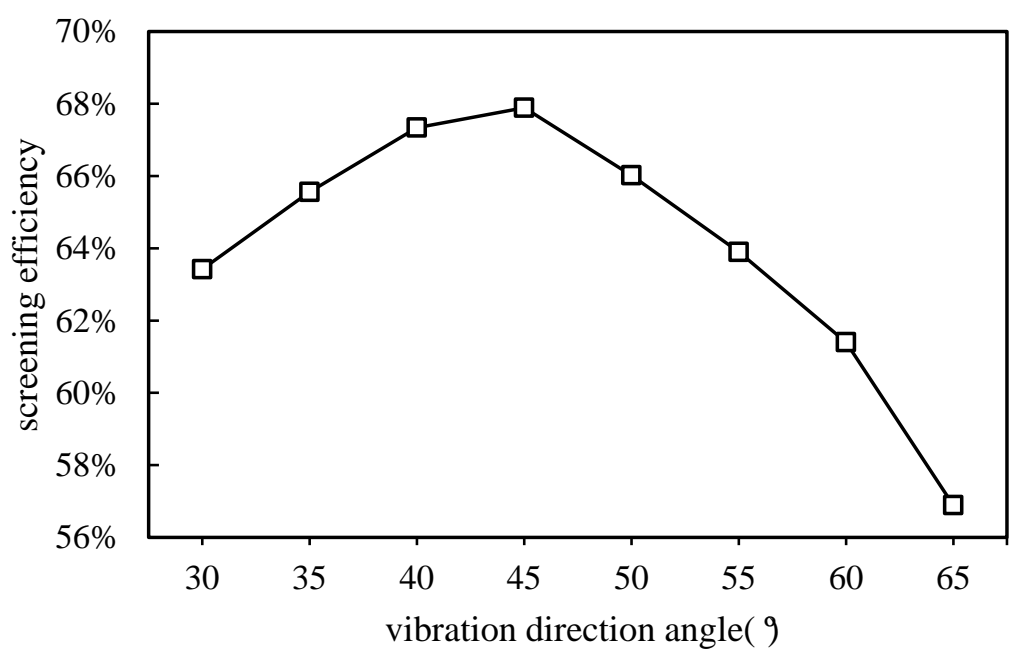

Figure 9. Screening efficiencies of a cantilevered vibrating sieve (CVS) for different vibration direction angle.

The screening efficiency is also affected by the vibration amplitude, as shown in Figure 10. Clearly, within a small range, the increase of amplitude improves the screening efficiency with $\beta=0^{\circ}$, $\mathrm{L}=380 \mathrm{~mm}, \omega=16 \mathrm{~Hz}$, and $\gamma=40^{\circ}$. When the amplitude is $2 \mathrm{~mm}$, screening efficiency reaches its maximum value of $68.76 \%$. However, a further increase in the amplitude causes screening efficiency to drop abruptly. The increase of amplitude within a small range mainly influences the bouncing of particles and increases screening efficiency to some extent. However, when the amplitude exceeds $4 \mathrm{~mm}$, particles are seriously thrown out of the working area, and screening efficiency declines.

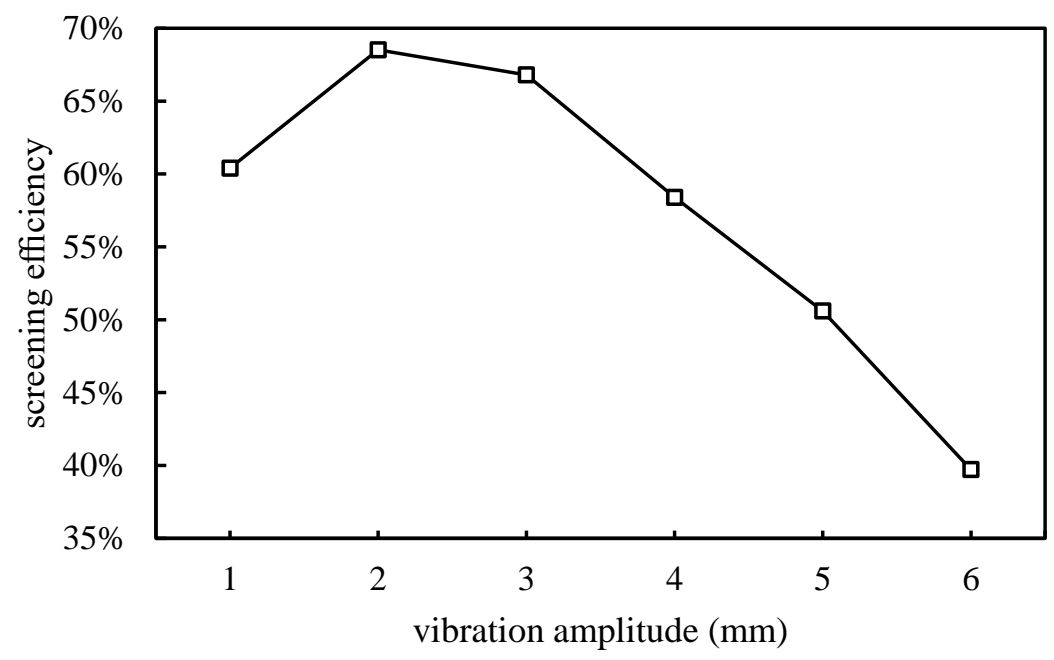

Figure 10. Screening efficiencies of a cantilevered vibrating sieve (CVS) for different vibration amplitude.

Figure 11 shows the influence of vibration frequency on screening efficiency. For the common vibration frequencies of $14-18 \mathrm{~Hz}$, screening efficiency maintains a high level of over $64 \%$. However, when vibration frequency increases to exceed $20 \mathrm{~Hz}$, the screening efficiency begins to decline. A large vibration frequency of the CVS may lead to a fast movement of the particles, which has a negative influence of the particles feeding-conveying-layering through the screen surface. It should be noted that the diameter of cantilevered sieve rod $\mathrm{d}=6 \mathrm{~mm}$, and according to Table 1 and Equation (8), one can show that the natural frequency of cantilevered rod is $29.31 \mathrm{~Hz}$. As the flexible deformation of 
the cantilevered rod cannot be achieved during the screening simulation, we cannot demonstrate the beneficial effect of the screening process at the natural frequency.

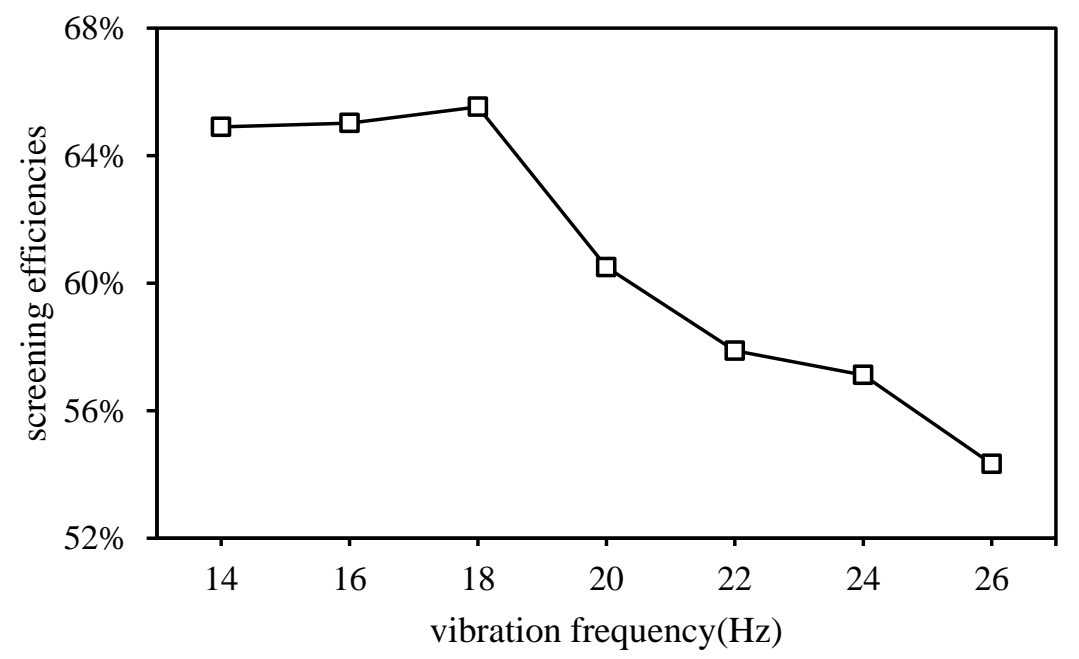

Figure 11. Screening efficiencies of a cantilevered vibrating sieve (CVS) for different vibration frequency.

\section{Conclusions}

(1) The proposed cantilevered vibrating sieve (CVS) is composed of cantilevered sieve rods. During the screen body oscillations, the sieve may experience additional bending vibrations. When the vibration frequency of screen body closely approaches the natural frequency, the additional bending vibration of cantilevered sieve rod reaches its peak value, and different amplitudes exist in the cantilevered rod from its fixed end to the free end.

(2) The CVS has a higher screen-penetrating probability than the traditional sieves, and the bending vibration of cantilevered sieve rod can crack the clusters of wet sticky materials on the sieve, cause near-aperture particles to experience rubbing motion, and then reduce sieve plugging.

(3) According to DEM analysis of the effect of the geometric parameters and vibration parameters of the sieve on screening efficiency, with the increase of sieve inclination angle and rod length, screening efficiency has a declining trend. Screening efficiency is at a high level under vibration direction angle of about $50^{\circ}$, vibration frequency of $25-30 \mathrm{~Hz}$, and amplitude of about $2 \mathrm{~mm}$.

Author Contributions: Conceptualization, L.P., H.F.; Methodology, L.P.; Software, H.F.; Formal Analysis, H.W.; Data Curation, Z.W.; Writing-Original Draft Preparation, H.H.; Writing-Review and Editing, L.P.; Writing-Revision, Z.W., H.Y.

Funding: This work is supported by the National Natural Science Foundation of China (Grant NO. 51705131, 51605138), the Fundamental Research Funds for the Central Universities (2018B22614), the Shandong Provincial Natural Science Foundation (Grant No. ZR2019PEE024), and the Project funded by China Postdoctoral Science Foundation (Grant NO. 2018T110568).

Acknowledgments: The authors are grateful to the anonymous reviewers for their constructive comments.

Conflicts of Interest: The authors declare no conflict of interest.

\section{References}

1. Peng, L.P.; Jiang, H.S.; Chen, X.H. A review on the advanced design techniques and methods of vibrating screen for coal preparation. Powder Technol. 2019, 347, 136-147. [CrossRef]

2. Cleary, P.W.; Wilson, P.; Sinnott, M.D. Effect of particle cohesion on flow and separation in industrial vibrating screens. Miner. Eng. 2018, 119, 191-204. [CrossRef]

3. Elskamp, F.; Kruggel-Emden, H. Extension of process models to predict batch screening results under the influence of moisture based on DEM simulations. Powder Technol. 2019, 342, 698-713. [CrossRef] 
4. Zhao, Y.; Liu, C.; Fan, M.; Wei, L. Research on acceleration of elastic flip-flow screen surface. Int. J. Miner. Process. 2000, 59, 267-274. [CrossRef]

5. Rotich, N.; Tuunila, R.; Elkamel, A.; Louhi-Kultanen, M. Dynamic and perturbative system analysis of granular material in a vibrating screen. Adv Powder Technol. 2017, 28, 3257-3264. [CrossRef]

6. Zhou, Z.; Huang, L.; Jiang, H.; Wen, P.; Zhao, L.; Zhao, Y.; Duan, C.; Luo, Z.; Wang, Z.; Liu, C.; et al. Kinematics of elastic screen surface and elimination mechanism of plugging during dry deep screening of moist coal. Powder Technol. 2019, 346, 452-461. [CrossRef]

7. Akbari, H.; Ackah, L.; Mohanty, M. Performance optimization of a new air table and flip-flow screen for fine particle dry separation. Int. J. Coal Prep. Util. 2017, 1-23. [CrossRef]

8. Song, B.-C.; Liu, C.-S.; Peng, L.-P.; Li, J. Dynamic analysis of new type elastic screen surface with multi degree of freedom and experimental validation. J. Cent. South Univ. 2015, 22, 1334-1341. [CrossRef]

9. Jiang, H.S.; Duan, C.L.; Wu, J.D.; Zhao, Y.M.; Liu, C.S.; Luo, Z.F.; Dong, L.; Zhang, B.; Wang, Z.Q.; Zhang, C.Y.; et al. Kinematics characteristics of the vibrating screen with rigid-flexible screen rod and the behavior of moist coal particles during the dry deep screening process. Powder Technol. 2017, 319, 92-101. [CrossRef]

10. Peng, L.P.; Li, F.M.; Dong, H.L.; Liu, C.S.; Zhao, Y.M.; Duan, C.L. Characteristics analysis of a novel centralized-driving flip-flow screen. Int. J. Min. Sci. Technol. 2014, 24, 195-200. [CrossRef]

11. Xiong, X.Y.; Niu, L.K.; Gu, C.X.; Wang, Y.H. Vibration characteristics of an inclined flip-flow screen panel in banana flip-flow screens. J. Sound Vib. 2017, 411, 108-128. [CrossRef]

12. Elskamp, F.; Kruggel-Emden, H. DEM simulations of screening processes under the influence of moisture. Chem. Eng. Res. Des. 2018, 136, 593-609. [CrossRef]

13. Zhao, L.L.; Zhao, Y.M.; Bao, C.Y.; Hou, Q.F.; Yu, A.B. Optimization of a circularly vibrating screen based on DEM simulation and Taguchi orthogonal experimental design. Powder Technol. 2017, 310, 307-317. [CrossRef]

14. Zhao, L.L.; Zhao, Y.M.; Bao, C.Y.; Hou, Q.F.; Yu, A.B. Laboratory-scale validation of a DEM model of screening processes with circular vibration. Powder Technol. 2016, 303, 269-277. [CrossRef]

15. Dong, K.; Esfandiary, A.H.; Yu, A. Discrete particle simulation of particle flow and separation on a vibrating screen: Effect of aperture shape. Powder Technol. 2017, 314, 195-202. [CrossRef]

16. Harzanagh, A.A.; Orhan, E.C.; Ergün, Ş.L. Discrete element modelling of vibrating screens. Miner. Eng. 2018, 121, 107-121. [CrossRef]

17. Davoodi, A.; Bengtsson, M.; Hulthén, E.; Evertsson, C. Effects of screen decks' aperture shapes and materials on screening efficiency. Miner. Eng. 2019, 139, 105699. [CrossRef]

18. Yin, Z.; Zhang, H.; Han, T. Simulation of particle flow on an elliptical vibrating screen using the discrete element method. Powder Technol. 2016, 302, 443-454. [CrossRef]

19. Jahani, M.; Farzanegan, A.; Noaparast, M. Investigation of screening performance of banana screens using LIGGGHTS DEM solver. Powder Technol. 2015, 283, 32-47. [CrossRef]

20. Li, Z.; Tong, X. Applications of the discrete element method and Fibonacci sequence on a banana screen. J. Eng. Des. Technol. 2017, 15, 2-12. [CrossRef]

21. Wang, Z.Q.; Liu, C.S.; Wu, J.D.; Jiang, H.S.; Zhao, Y.M. Impact of screening coals on screen surface and multi-index optimization for coal cleaning production. J. Clean. Prod. 2018, 187, 562-575. [CrossRef]

22. Rao, S.S. Vibration of Continuous Systems; Wiley: New York, NY, USA, 2007.

23. Vibration Screen with Cantilever Mesh. GB/T 26506-2011; Stands Press of China: Beijing, China, 2011.

(C) 2019 by the authors. Licensee MDPI, Basel, Switzerland. This article is an open access article distributed under the terms and conditions of the Creative Commons Attribution (CC BY) license (http://creativecommons.org/licenses/by/4.0/). 